\title{
Mechanical Cardiac Tamponade as an Initial Presentation of Malignant Lymphoma: Case Report
}

\author{
Bouziane M*, Kherraf A, Abdulhakeem M, Arous S, Nouamou I, Benouna G, Drighil A, Azzouzi L and Habbal R \\ Department of Cardiology, Ibn Rochd University hospital of Casablanca, Morocco
}

Submission: July 26, 2020; Published: August 14, 2020

*Corresponding author: Maha Bouziane, Department of Cardiology, P37 Ibn Rochd University hospital of Casablanca, Quartier des Hôpitaux, Casablanca, Morocco

\section{Abstract}

Cardiac tamponade results from an accumulation of pericardial fluid under pressure, leading to impaired cardiac filling and haemodynamic compromise. In malignant lymphoma, cardiac and pericardial involvement, even though relatively uncommon, can be one early manifestations of this neoplastic disease. We describe a case of a 21 year old female with no medical history, whose first presentation for mediastinal lymphoma was a mechanical cardiac tamponade.

Keywords: Mechanical cardiac tamponade; Mediastianl lymphoma; Diagnosis

\section{Introduction}

Cardiac tamponade is a life-threatening setting due to slow or rapid pericardial build-up of fluid with subsequent compression of the heart. One of the many causes of it is neoplastic diseases, such as lymphomas.

There are several explanations regarding pericardial effusion in lymphoma. It may be due to lymphatic and blood spread. Effusion may be caused by an obstacle of the lymphatic and venous drainage of pericardial fluid. It may also not involve the pericardium. The lymphatic channels from visceral pericardium have drainage at the aortic root. This drainage spot can be blocked either by malignant deposits or via compression due to enlarged lymph nodes [1].

Malignant lymphoma can arise in or spread to the mediastinum. Mediastinal lymphadenopathy due to lymphoma may present early due to rapid growth of the tumor and compression caused by it [1].

The objective of this observation is to report the case of a mechanical tamponade caused by a compression of the right heart chambers by a probable mediastinal lymphoma.

\section{Case Report}

We report the case of a 21-year-old female patient, without any known medical history, who was admitted to the emergency department for a stage III to IV dyspnea of NYHA and right chest pain that had been progressing for 3 weeks.

On clinical examination, her blood pressure was 100/60 mmhg, heart rate was 96 beats/minute, with muffled heart sounds, elevated jugular veins pressure, signs of right pleural effusion and a supraclavicular lymphadenopathy.

The electrocardiogram revealed a sinus tachycardia, a decreased electrocardiographic voltage without electrical alternans. The chest X-ray showed total opacification of the right hemithorax with an enlarged cardiac silhouette (Figure 1).

A thoracic CT scan was performed showing a large right mediastinal mass measuring $174 \times 40 \times 86 \mathrm{~mm}$, causing an upper right segmental collapse and significant compression of the cardiac chambers, as well as a moderate pleural effusion (Figure 2 \& 3). The transthoracic echocardiography objectified a $35 \mathrm{~mm}$ pericardial effusion over the right heart chambers, with a preserved LV function (Figure 4). 


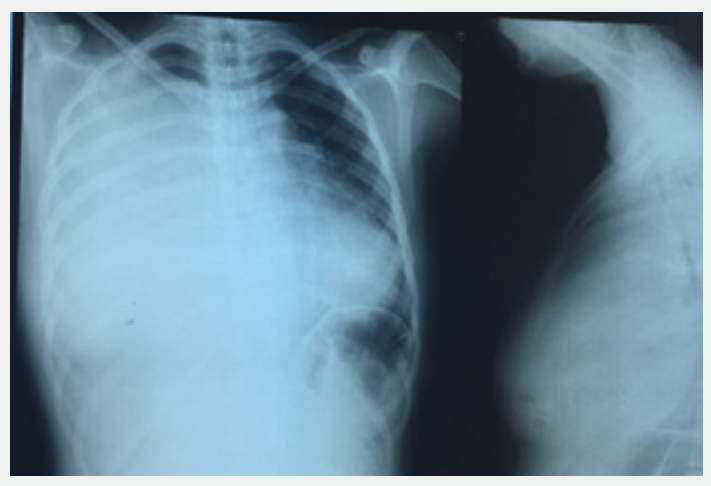

Figure 1: Chest X-ray showing an opacification of the right hemithorax, with an enlarged cardiac silhouette.

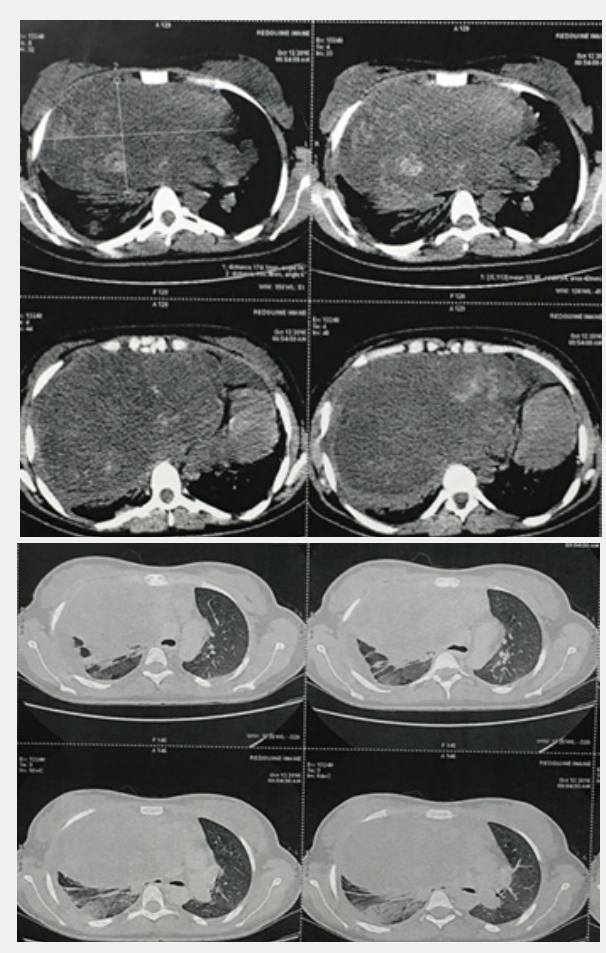

Figure 2-3: Thoracic CT scan displaying a mediastinal mass causing a segmental collapse and a compression of the heart.

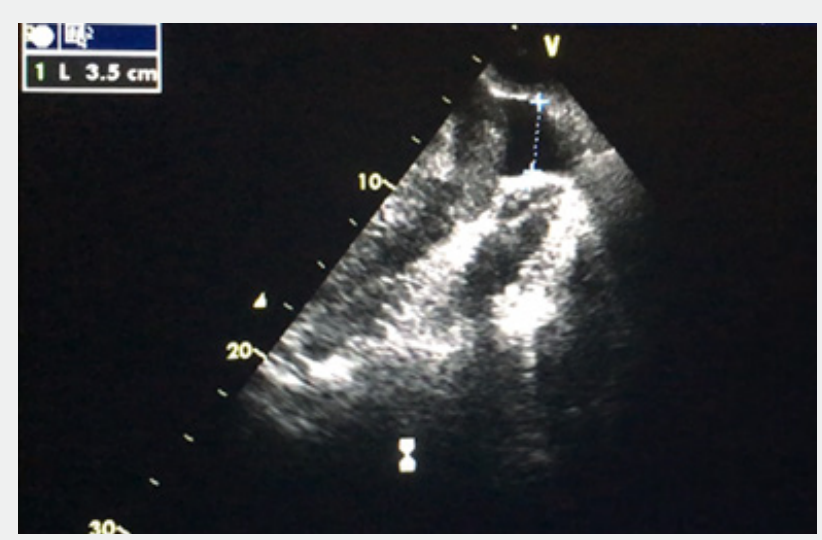

Figure 4: Two-dimensional echocardiogram illustrating a $35 \mathrm{~mm}$ pericardial effusion. 
Routine blood tests showed a hypochromic microcytic anemia (Hemoglobin at 9.7g/dl), normal white blood cell count (9800), elevated platelets (578000), normal prothrombin levels at $82 \%$, and elevated fibrinogen at $6.4 \mathrm{~g} / \mathrm{l}$; and abnormal hepatic enzymes with ALT at $110 \mathrm{IU} / \mathrm{l}$ and AST at $60 \mathrm{IU} / \mathrm{l}$. Serological tests for hepatitis, HIV and syphilis were negative. A thoracentesis was done revealing an exudate pleural fluid. A bone marrow biopsy was also performed objectifying a lymphoid infiltration and overactive bone marrow.

Multiple transparietal pleural biopsies and a biopsy of the supraclavicular lymphadenopathy were non- conclusive (inflammation, necrosis and lymphadenitis). After discussing the patient's case by a multidisciplinary team, lymphoma was considered the most likely diagnosis and chemotherapy wasn't possible in her case. A trial of corticosteroid therapy was started, with a twice daily $120 \mathrm{mg}$ dose of methylprednisolone, allowing a relative decompression of the heart chambers. The patient was referred for surgical pericardiectomy and diagnostic mediastinoscopy.

\section{Discussion}

All diseases that can involve the pericardium can cause a pericardial effusion. Therefore, idiopathic pericarditis and numerous infections, neoplasms, autoimmune diseases, radiation, post-ST segment elevation myocardial infarction (STEMI) pericarditis, and noxious substances, for example, blood, may be responsible. Some studies have suggested that as many as $20 \%$ of pericardial effusions without an obvious cause after routine evaluation constitute the initial manifestation of a cancer [2].

Indeed, Perek B et al concluded in their study of 81 previously healthy patients, which cardiac tamponade was the main symptom of cancer, especially of the lungs [3].

Mediastinal masses are rare and are often found incidentally; however, finding the exact etiology of the tumor is relatively difficult. The most common tumors are: small cell carcinoma (40\%), lymphoma (20\%), thymomas (16\%). The definitive diagnosis is histological [4].

Cardiac presentaions from lymphomas can be primary or secondary. Primary cardiac lymphoma concerns the heart or pericardium and is considered a rare presentation of lympohmas, accounting for less than $1 \%$ of all extranodal localization of these tumors. However, masses involving other sites, such as mediastinal lymphadenopathy or disease below the diaphragm, most likely represent secondary cardiac lymphomatous involvement. In some studies, secondary heart involvement by lymphoma was identified at postmortem in $10 \%$ to $30 \%$ of the cases. Lymphomas represented more than $9 \%$ of the total metastases to the heart, and up to $20 \%$ of patients with lymphoma are found, at autopsy, to have cardiac involvement [5].
There are three main entities of mediastinal lymphomas: $\mathrm{T}$ lymphoblastic lymphoma, mediastinal (thymic) diffuse large B cell lymphoma, and classical Hodgkin lymphoma [6].

Cardiac involvement of a malignant lymphoma is usually a late manifestation of the disease; it is difficult to make a definite diagnosis in some cases. Therefore, treatment may be started before histological confirmation. In our case, the definitive diagnosis of lymphoma wasn't possible after many transparietal pleural biopsies and the biopsy of the supraclavicular lymphadenopathy, so after a multidisciplinary discussion, it was decided to start a trial corticosteroid therapy.

Ischiwata et al. [7] described a rare case of malignant lymphoma with diffuse cardiac and pericardium involvement that initially presented as congestive cardiac failure. A tissue diagnosis of the mediastinal mass could not be performed due to the patient's generally poor condition. The patient received corticosteroid therapy, but died 42 days after her admission.

\section{Conclusion}

Mechanical cardiac tamponade is both a medical and surgical emergency that can complicate mediastinal tumors, and may in some cases of hemodynamically unstable patients, delay the management of the underlying etiology. For histologically unconfirmed compressive mediastinal lymphomas, trial corticosteroid therapy may be considered.

\section{Conflict of interest: None.}

\section{References}

1. Hajra A, Bandyopadhyay D, Layek M, Mukhopadhyay S (2015) Cardiac Tamponade as Initial Presentation of Hodgkin Lymphoma. J Clin Imaging Sci 5: 67.

2. Azarbal A, LeWinter MM (2017) Pericardial Effusion. Cardiol Clin 35(4): 515-524.

3. Perek B, Tomaszewska I, Stefaniak S, Katynska I, Jemielity M (2016) Cardiac tamponade - unusual clinical manifestation of undiagnosed malignant neoplasm. Neoplasma 63(4): 601-606.

4. Neffati O, Smadhi H, Benhamad W, Ayari A, Greb D, et al. (2015) Étiologies des masses médiastinales. Revue des Maladies Respiratoires 32(Supplement): A104.

5. Muthusamy P, Ebrom S, Cohle SD, Khan N (2014) Pericardial involvement as an initial presentation of anaplastic large cell lymphoma. Can Fam Physician 60(7): 638-641.

6. Chetaille B (2010) Lymphomes médiastinaux: anatomie pathologique [Mediastinal lymphomas: histopathology]. Rev Pneumol Clin 66(1): 28-31.

7. Ishiwata T, Harada N, Ko R, Hara M, Sekiya M, et al. (2012) Malignant lymphoma with diffuse cardiac involvement detected by multiple imaging examinations: a case report. J Med Case Rep 6: 193. 
Your next submission with Juniper Publishers will reach you the below assets

- Quality Editorial service

- Swift Peer Review

- Reprints availability

- E-prints Service

- Manuscript Podcast for convenient understanding

- Global attainment for your research

- Manuscript accessibility in different formats

( Pdf, E-pub, Full Text, Audio)

- Unceasing customer service

Track the below URL for one-step submission https://juniperpublishers.com/online-submission.php 